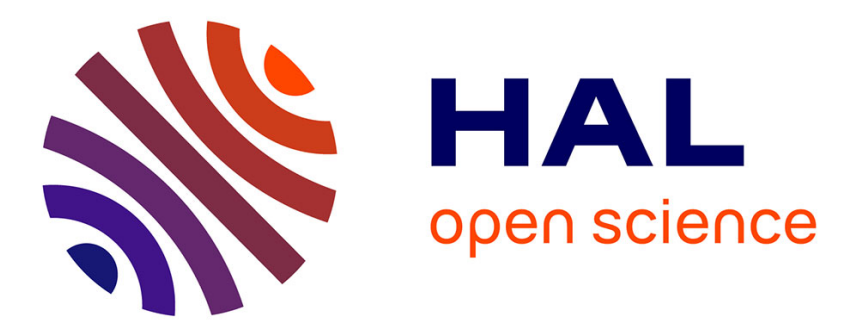

\title{
A computational mechanics approach to assess the link between cell morphology and forces during confined migration
}

\author{
Denis Aubry, Hawa Thiam, Matthieu Piel, Rachele Allena
}

\section{- To cite this version:}

Denis Aubry, Hawa Thiam, Matthieu Piel, Rachele Allena. A computational mechanics approach to assess the link between cell morphology and forces during confined migration. Biomechanics and Modeling in Mechanobiology, 2015, 14 (1), pp.143-157. 10.1007/s10237-014-0595-3 . hal-01083871

\section{HAL Id: hal-01083871 https://hal.science/hal-01083871}

Submitted on 18 Nov 2014

HAL is a multi-disciplinary open access archive for the deposit and dissemination of scientific research documents, whether they are published or not. The documents may come from teaching and research institutions in France or abroad, or from public or private research centers.
L'archive ouverte pluridisciplinaire HAL, est destinée au dépôt et à la diffusion de documents scientifiques de niveau recherche, publiés ou non, émanant des établissements d'enseignement et de recherche français ou étrangers, des laboratoires publics ou privés. 


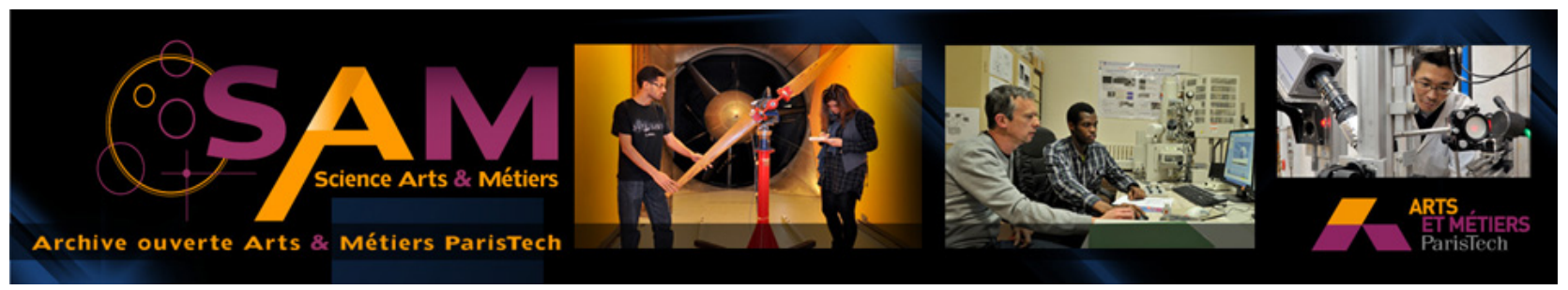

\section{Science Arts \& Métiers (SAM)}

is an open access repository that collects the work of Arts et Métiers ParisTech researchers and makes it freely available over the web where possible.

This is an author-deposited version published in: http://sam.ensam.eu

Handle ID: .http://hdl.handle.net/10985/8927

\section{To cite this version :}

Denis AUBRY, Hawa THIAM, Matthieu PIEL, Rachele ALLENA - A computational mechanics approach to assess the link between cell morphology and forces during confined migration Biomechanics and Modeling in Mechanobiology p.nn - 2014 


\title{
A computational mechanics approach to assess the link between cell morphology and forces during confined migration
}

\author{
D. Aubry · H. Thiam • M. Piel · R. Allena
}

\begin{abstract}
Confined migration plays a fundamental role during several biological phenomena such as embryogenesis, immunity and tumorogenesis. Here, we propose a twodimensional mechanical model to simulate the migration of a HeLa cell through a micro-channel. As in our previous works, the cell is modelled as a continuum and a standard Maxwell model is used to describe the mechanical behaviour of both the cytoplasm (including active strains) and the nucleus. The cell cyclically protrudes and contracts and develops viscous forces to adhere to the substrate. The micro-channel is represented by two rigid walls, and it exerts an additional viscous force on the cell boundaries. We test four channels whose dimensions in terms of width are i) larger than the cell diameter, ii) sub-cellular, ii) sub-nuclear and iv) much smaller than the nucleus diameter. The main objective of the work is to assess the necessary conditions for the cell to enter into the channel and migrate through it. Therefore, we evaluate both the evolution of the cell morphology and the cell-channel and cell-substrate surface forces, and we show that there exists a link between the two, which is the essential parameter deter-
\end{abstract}

Electronic supplementary material The online version of this article (doi:10.1007/s10237-014-0595-3) contains supplementary material, which is available to authorized users.

\section{Aubry}

Laboratoire MSSMat UMR CNRS 8579, Ecole Centrale Paris, 92295 Châtenay-Malabry, France

H. Thiam · M. Piel

Biologie systémique de la division et de la polarité cellulaire, Institut Curie UMR 144, 12 Rue Lhomond, 75005 Paris, France

R. Allena ( $\varangle)$

Arts et Metiers ParisTech, LBM, 151 Bd de l'hôpital,

75013 Paris, France

e-mail: Rachele.allena@ensam.eu mining whether the cell is permeative, invasive or penetrating.

Keywords Confined cell migration · Continuum mechanics $\cdot$ Computational mechanics $\cdot$ Forces

\section{Introduction}

In our previous works (Allena and Aubry 2012; Allena 2013), we have presented numerical models which helped to understand the mechanisms controlling cell motility on twodimensional (2D) flat surfaces. Nevertheless, during many biological processes such as embryogenesis, immunity and tumorogenesis, cell migration takes place in confined environments of tissues (Friedl and Wolf 2010). In these cases, cell locomotion is influenced by the presence of attractant molecules, but also by the morphology of the extracellular matrix (ECM). In fact, the surrounding tissues may vary in terms of heterogeneity, fibres density and organization. As shown both experimentally (Erler and Weaver 2009; Wolf et al. 2009; Egeblad et al. 2010; Friedl and Wolf 2010) and theoretically (Zaman et al. 2005, 2006, 2007; Scianna et al. 2013), the width of the ECM pores, the degree of ECM alignment as well as the ECM stiffness are fundamental parameters, which determine how and how much the ECM steers or inhibits the cell movement. Therefore, the cell needs to continuously adapt its shape and consequently its migratory behaviour. In tumorogenesis for instance, cancer cells develop an invasive behaviour, which allows them to enter and progressively invade healthy tissue as they are constantly exposed to biomechanical and biophysical stimuli. Such adaptation requires an internal reorganization of both the cytoskeleton and the embedded organelles, among which the nucleus is the stiffest and the most voluminous. Consequently, it has become essen- 
tial to quantitatively assess the cell ability to deform as well as which mechanical forces the cell has to develop in order to move forward within a confined micro-structure.

In the last few years, several experimental studies have tried to provide such data. Systems like collagen gels or lattices are commonly used to simulate cell migration in confined connective tissues (Wolf et al. 2009). Although very simplified, such systems are highly complex and difficult to control since many physical parameters (i.e. gel density and elasticity, local constrictions) may affect the global mobility of the cell and furthermore fail to reproduce spatial tracks or obstacles (Provenzano et al. 2008; Wolf et al. 2009; Egeblad et al. 2010). More recently, it has been possible to better control, vary and tune the geometrical characteristics of the patterned micro-structure using micro-laser techniques (Ilina et al. 2011) or photolithography (Heuzé et al. 2011). In the latter work, cells migrate through straight micro-channels made of silicone rubber (i.e. polydimethylsiloxane, PDMS), whose sub-cellular dimensions vary between 2 and $10 \mu \mathrm{m}$ in width and highly depend on cell type. Such an approach has provided interesting results for cancer cells (Irimia and Toner 2009; Ronot et al. 2000), immune cells (Irimia et al. 2007; Faure-André et al. 2008) and neurons (Taylor et al. 2005). Micro-channels may be modulated in order to investigate specific biological problems such as trans-migration ability within a well-defined geometry or the influence of the substrate stiffness by letting channel material vary. Additionally, more complex geometries can be obtained to force the cell to take turns and explore its 2D confined environment.

From a numerical point of view, many models have been proposed to simulate single cell migration on 2D flat surfaces or in three-dimensional (3D) environment (Rangarajan and Zaman 2008). Such models have used different approaches resulting in force-based dynamics models (Zaman et al. 2005, 2006), stochastic models to simulate persistent random walks (Tranquillo and Lauffenburger 1987; Tranquillo et al. 1988; Stokes et al. 1991; Stokes and Lauffenburger 1991), models reproducing the movement of cancer cell spheroids (McElwain and Ponzo 1977; McElwain 1978; McElwain et al. 1979), Monte Carlo models (Zaman et al. 2007; Scianna and Preziosi 2013; Scianna et al. 2013) or purely mechanical models (Allena and Aubry 2012; Allena 2013). Active gel layers submitted to external forces have been used to represent acto-myosin cells migrating in a free (Recho and Truskinovsky 2013; Recho et al. 2013) or confined (Hawkins et al. 2009; Hawkins and Voituriez 2010) environment. Scianna and Preziosi (Scianna and Preziosi 2013) have presented a cellular potts model (CPM), which reproduces an experimental assay very similar to those used in (Taylor et al. 2005; Irimia et al. 2007; Faure-André et al. 2008; Irimia and Toner 2009; Rolli et al. 2010; Heuzé et al. 2011). In this model, the cell is modelled as a discrete physical unit, including the cytosol and the nucleus, while channels of different widths constitute the migration chamber. The authors have investigated the invasiveness of tumour cells by evaluating their displacement and velocity as well as their deformability, which seems to be strongly linked to the deformability of the nucleus. In (Tozluoğlu et al. 2013), a hybrid agent-based finite element model is proposed to evaluate the migration strategy of the cell in different environments such as confinement. The model is able to simulate both the protrusion-contraction and the membrane blebbing modes of migration. Therefore, the authors estimate the effects of the ECM geometry on the relationship between cell velocity, contractility and adhesion, and they also find interesting effects of membrane blebbing on cell velocity and morphology. Finally, in (Giverso et al.), an energetic continuum approach is employed to investigate the necessary condition for which a cell migrate through a cylindrical channel. They consider the nucleus either as an elastic membrane surrounding a liquid droplet or as an incompressible elastic material. By taking into account and balancing different forces exerted by and on the cell during confined movement, they are able to determine the minimal size of the cylindrical structure and they observe that cell ability to migrate through it depends on both nucleus stiffness and adhesion to ECM.

\subsection{Objective of the present work}

In the present paper, a finite element model that reproduces the experimental set-up used in (Heuzé et al. 2011) for HeLa cells is proposed, which is based on the following hypotheses:

- the 2D geometry represents a top view of the global structure, and a plane stress hypothesis has been made;

- as in (Giverso et al.), a purely mechanical approach is used to describe the cell behaviour. However, a different mathematical method is applied. In fact, the decomposition of the deformation gradient is employed to consider both the active (i.e. protrusion and contraction) and the elastic (i.e. strains generated by the interaction with the environment) strains undergone by the cell;

- contrary to previous works (Scianna and Preziosi 2013; Scianna et al. 2013; Tozluoğlu et al. 2013), the cell is modelled as a continuum. Nonetheless, both the cytoplasm and the nucleus have been originally represented through two characteristic functions, and a standard Maxwell model has been used to describe their viscoelastic behaviour (Allena and Aubry 2012; Allena 2013; Tozluoğlu et al. 2013);

- the cell is able to cyclically protrude and contract. Such active strains are triggered respectively by the polymerization and depolymerization of the actin filaments and are synchronized with the viscous adhesion forces between the cell and the substrate (Allena and Aubry 2012; Allena 2013); 
Fig. 1 Geometry of the cell (a) and frontal and rear adhesion surfaces $(\mathbf{b})$

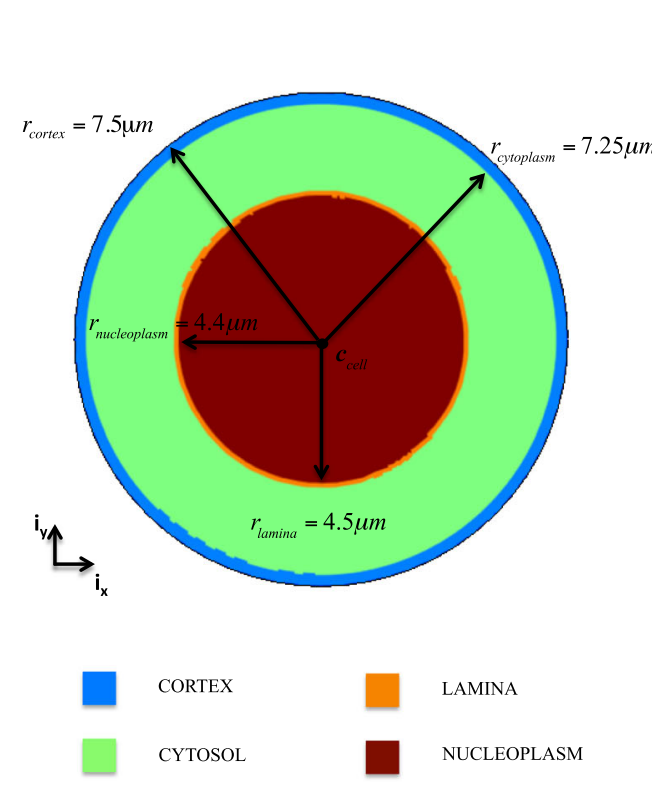

(a)

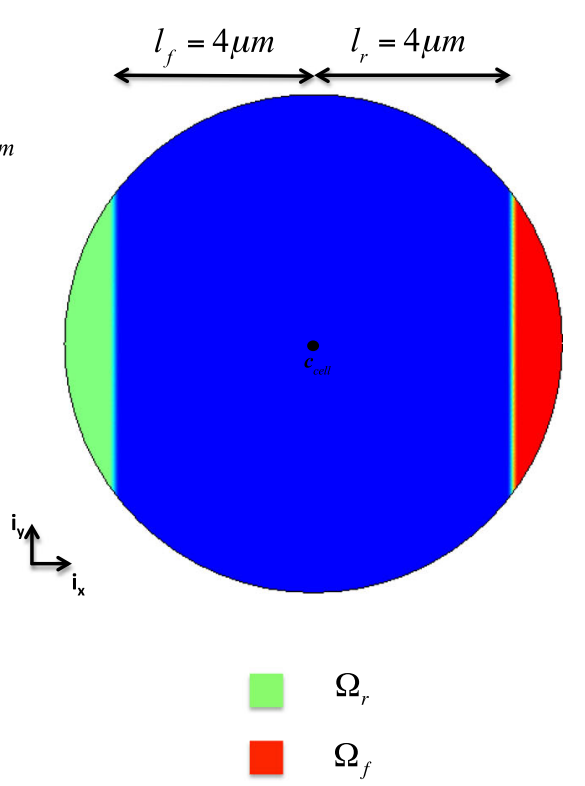

(b)
- the micro-channel is represented by two rigid walls, which are described by two characteristic functions, and exerts an additional normal viscous force on the cell boundaries when contact condition is fulfilled.

The main objective of our work is to assess the necessary conditions for the cell to enter into the channel and migrate through it. In order to do so, we test four different channels whose dimensions in width are i) larger than the cell diameter, ii) sub-cellular, iii) sub-nuclear and iv) much smaller than the nucleus diameter. We analyse the evolution of the cell morphology by consistently comparing it with experimental observations, and we classify the cell behaviour according to the covered distance inside the channel. Additionally, we evaluate both the cell-substrate and the cell-channel surface forces during migration, and we find that there exists a link between such forces and the changes in cell shape, which may be essential in determining the invasive behaviour of the cell.

The paper is organized as follows: in Sect. 2, the geometry of the cell, the constitutive model and the mechanical approach are described. In Sect. 3, the results of the numerical simulations are presented. First, we analyse the cell behaviour (Sect. 3.1). Second, we evaluate the mechanical cellsubstrate and cell-channel surface forces (Sect. 3.2), and we find the necessary conditions determining whether the cell is penetrating, invasive or permeative.

\section{The model}

In this section, we provide the general framework of the model. First, we describe the geometry of the cell includ- ing the cytoplasm and the nucleus. Second, we focus on the mechanics of the system. Specifically, we introduce the standard Maxwell models, which are used to reproduce the viscoelastic behaviour of the nucleus and the cytoplasm. Third, the intra-synchronization is presented. As in our previous works (Allena and Aubry 2012; Allena 2013), this represents the key ingredient of the cell movement. In fact, we show how the cyclic active strains (i.e. protrusion and contraction) are strongly coupled with the viscous forces generated by the cell to adhere to the substrate and necessary to efficiently move forward. Finally, we describe the geometry of the micro-channel and the associated viscous force exerted on the cell boundaries, which allows the cell to squeeze and pass (or not) through it.

\subsection{Cell geometry}

HeLa cells are human cells with a rather rounded initial shape and a diameter of about $15 \mu \mathrm{m}$ (Ronot et al. 2000; Ngalim et al. 2013). For the numerical model, the geometry of the cell has been simplified by a circular domain $\Omega_{\text {cell }}$ of radius $r_{\text {cell }}$ (Fig. 1a). Here, we consider two main components of the cell: the cytoplasm ( $\left.\Omega_{\text {cytoplasm }}\right)$ and the nucleus $\left(\Omega_{\text {nucleus }}\right)$ (Fig. 1a, Sect. 5.1). Additionally, the cell cyclically generates a frontal $\left(\Omega_{f}\right)$ and a rear $\left(\Omega_{r}\right)$ adhesion region in order to move forward (Allena and Aubry 2012; Allena 2013) (Fig. 1b, Sect. 5.1).

\subsection{Constitutive model and mechanics of the cell}

Both the nucleus and the cytoplasm are assumed to be viscoelastic materials, and their behaviour is described by two 
standard Maxwell models (Larson 1998) (Sect. 5.2). On one hand, the nucleus is composed by the nuclear lamina $\Omega_{\text {lamina }}$ (the solid phase, Sects. 5.1 and 5.2), which surrounds the viscoelastic nucleoplasm $\Omega_{\text {nucleoplasm }}$ (the fluid phase, Sects. 5.1 and 5.2). On the other hand, the cytoplasm is essentially made of a solid phase represented by the cell cortex $\Omega_{\text {cortex }}$ (Sects. 5.1 and 5.3) and a fluid-like phase, the cytosol $\Omega_{\text {cytosol }}$ (Sects. 5.1 and 5.3) in which the organelles such as the actin filaments are embedded. As in our previous works (Allena and Aubry 2012; Allena 2013), we assume that the polymerization of the actin filaments inside the cytosol, which mostly occurs at the front of the cell (Schaub et al. 2007), generates the protrusive force at the leading edge, and their contraction due to binding of myosin generates the contractile stress at the rear of the cell (Mogilner 2009). Such active strains triggering the deformability of the cell are then described through a deformation tensor $\boldsymbol{F}_{\mathrm{cytosol}, a}$ (Sects. 2.3 and 5.3) in the fluid-like branch of the symbolic standard Maxwell model of the cytoplasm.

As described in (Allena and Aubry 2012; Allena 2013), the global equilibrium of the system is expressed as

$$
\rho a=\operatorname{Div}_{p}\left(J \sigma \boldsymbol{F}^{-T}\right)+\boldsymbol{f}_{\mathrm{adh}}+\boldsymbol{f}_{\text {channel }}
$$

where $\rho$ is the cell density, $\boldsymbol{a}$ is the acceleration, $\boldsymbol{D i v}_{p}$ is the divergence with respect to the initial position $p, J$ is the determinant of the deformation gradient $\boldsymbol{F}$ and $\boldsymbol{A}^{-T}$ denotes the inverse transpose of the matrix $\boldsymbol{A}$ (Holzapfel 2000; Taber 2004). $\boldsymbol{f}_{\text {adh }}$ and $\boldsymbol{f}_{\text {channel }}$ indicate, respectively, the viscous adhesion forces between the cell and the substrate (Sect. 2.3) and the viscous force exerted by the channel on the cell boundaries (Sect. 2.4). Here, all the body forces but the inertial effects are neglected (Gracheva and Othmer 2004; Allena and Aubry 2012; Allena 2013).

\subsection{Intra-synchronization}

To describe the oscillating movement of the cell, two main assumptions have been made:

1) the active strains of protrusion and contraction are only applied in the cytosol. In fact, as in our previous works (Allena and Aubry 2012; Allena 2013), we assume that the oscillatory movement of the cell is triggered by the periodic polymerization and depolymerization of the actin filaments, which are embedded in the cytosol. The former only occurs at the front of the cell, while the latter takes place from the front towards the rear of the cell. Therefore, although the nucleus does not undergo any active strain, it will interact with the surrounding cytosol apart from the protrusion phase (Friedl et al. 2011);

2) although the cell may form multiple pseudopodia (Allena 2013), here only one is generated in the direction of migration, which, to reproduce the experimental set-up where the cell is constrained into a micro-channel (Heuzé et al. 2011), corresponds to the horizontal axis $\boldsymbol{i}_{x}$.

Therefore, the solid active deformation tensor $\boldsymbol{F}_{\mathrm{cytosol}, a}$ reads

$\boldsymbol{F}_{\mathrm{cytosol}, a}= \begin{cases}e_{a 0} \sin \left(2 \pi \frac{t}{T}\right) h_{\mathrm{cytosol}, \text { front }} \boldsymbol{i}_{x} \otimes \boldsymbol{i}_{x} & \text { if } \sin \left(2 \pi \frac{t}{T}\right)>0 \\ \frac{e_{a 0}}{2} \sin \left(2 \pi \frac{t}{T}\right) h_{\mathrm{cytosol}} \boldsymbol{i}_{x} \otimes \boldsymbol{i}_{x} & \text { if } \sin \left(2 \pi \frac{t}{T}\right)<0\end{cases}$

where $e_{a 0}$ is the amplitude of the active strain, $t$ is time, $T$ is the migration period, $h_{\text {cytosol }}$ and $h_{\text {cytosol, front }}$ are two characteristic functions (Sect. 5.1) and $\otimes$ indicates the tensorial product.

As shown in (Allena and Aubry 2012), in order to be able to effectively migrate, the cell must adhere on the substrate otherwise it would only deform on place. Thus, an intra-synchronization is required which coordinates the cyclic protrusion-contraction deformations with the adhesion forces $f_{\text {adh }}$ (Eq. 1) generated between the cell frontal and rear adhesion surfaces and the underneath substrate. As in previous works (Phillipson et al. 2006; Sakamoto et al. 2011; Allena and Aubry 2012; Allena 2013), such forces are assumed to be viscous and may be distinguished into a frontal $\left(f_{\text {adh }, f}\right)$ and a rear $\left(f_{\text {adh }, r}\right)$ force as follows

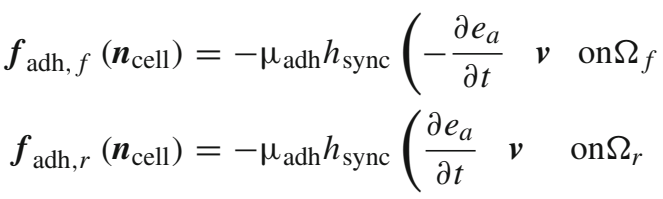

with $\boldsymbol{n}_{\text {cell }}$ the outward normal to the cell boundary, $\mu_{\text {adh }}$ the friction coefficient and $v$ the velocity. The characteristic function $h_{\text {sync }}$ is the key ingredient of the preceding equations since it couples the adhesion forces with the active strains, which results in the intra-synchronization mentioned above. Thus, we observe two main phases during the migratory movement of the cell: i) the protrusion and the adhesion at the rear edge; ii) the contraction and the adhesion at the frontal edge.

\subsection{Micro-channel}

Here, we want to reproduce the micro-channel-based assay presented in (Heuzé et al. 2011). Thus, the micro-channel domain $\Omega_{\text {channel }}$ is represented by two pseudo-elliptical rigid walls with no top roof (Sect. 5.4).

When the cell enters into the micro-channel, it is then submitted to a viscous force $f_{\text {channel }}$ (Eq. 1), which can be distinguished into an upper $\left(f_{\text {channel, } u w_{i}}\right)$ and a lower $\left(f_{\text {channel, } l w_{i}}\right)$ force as follows 


$$
\begin{aligned}
& \boldsymbol{f}_{\text {channel }, u w_{i}}\left(\boldsymbol{n}_{u w, i}\right) \\
& =-\mu_{\text {channel }} \frac{1}{\left(l_{u w, i}+1\right)^{8}+\alpha}\left(\frac{\partial \boldsymbol{u}}{\partial t}, \boldsymbol{n}_{u w, i} \quad n_{u w, i} \quad \text { on } \partial \Omega_{u w, i}\right. \\
& \boldsymbol{f}_{\text {channel }, l w_{i}}\left(\boldsymbol{n}_{l w, i}\right) \\
& =-\mu_{\text {channel }} \frac{1}{\left(l_{l w, i}+1\right)^{8}+\alpha}\left(\frac{\partial \boldsymbol{u}}{\partial t}, \boldsymbol{n}_{l w, i} \quad \boldsymbol{n}_{l w, i} \quad \text { on } \partial \Omega_{l w, i}\right.
\end{aligned}
$$

where $\mu_{\text {channel }}$ is the viscosity of the micro-channel, $l_{u w, i}$ and $l_{l w, i}$ are two level set functions (Sect. 5.4), $\alpha$ is a constant and $\boldsymbol{n}_{u w, i}$ and $\boldsymbol{n}_{l w, i}$ are the outward normal to the boundaries $\partial \Omega_{u w, i}$ and $\partial \Omega_{l w, i}$ of the upper and lower wall, respectively, which are here originally calculated (Sect. 5.4) (the subscript ' $i$ ' indicates the channel number as explained in Sect. 3.1 and 5.4). Finally, $(\boldsymbol{a}, \boldsymbol{b})$ defines the scalar product between two vectors.

\section{Results}

The numerical simulations have been run using the finite element software COMSOL Multiphysics ${ }^{\circledR} 3.5 \mathrm{a}$. As described in Sect. 2.2, the viscoelastic behaviour of the cell has been taken into account. The components of the cytoplasm and the nucleus have been implicitly described by specific characteristic functions (Sect. 5.1) in order to be able to define the parameters of the standard Maxwell models. The radius $r_{\text {cortex }}, r_{\text {cytosol }}, r_{\text {lamina }}$ and $r_{\text {nucleoplasm }}$ of the HeLa cell have been fixed to $7.5,7.25,4.5$ and $4.4 \mu \mathrm{m}$, respectively. Then, the cell cortex and the nuclear lamina have a thickness $t_{\text {cortex }}$ and $t_{\text {lamina }}$ of $0.25 \mu \mathrm{m}$ (Pesen and Hoh 2005; Tinevez et al. 2009; Jiang and Sun 2013) and $0.1 \mu \mathrm{m}$ (Righolt et al. 2010), respectively. The nominal values of the Young moduli $E_{\text {cortex, } 0}$ of the cell cortex and $E_{\text {cytosol,0 }}$ of the cytosol have been chosen equal to 100 and $10 \mathrm{~Pa}$ (Crick and Hughes 1950). For the nucleus, assuming that its stiffness is mostly provided by the nuclear lamina, we have set $E_{\text {lamina, } 0}$ and $E_{\text {nucleoplasm,0 }}$ to 3,000 Pa (Caille et al. 2002; Dahl et al. 2008) and $25 \mathrm{~Pa}$ (Vaziri et al. 2006), respectively. According to a simple spatial homogenization approach (Christensen 1991; Larson 1998), such moduli have then been recalculated according to the surface occupied by each component in the cell to obtain $E_{\text {cortex }}, E_{\text {cytosol }}, E_{\text {lamina }}$ and $E_{\text {nucleoplasm }}$ (Table 1). Since we consider here that the cell cortex and the nuclear lamina are rather elastic, while the cytosol and the nucleoplasm are rather viscoelastic, the Poisson's ratios $v_{\text {cortex }}$ and $v_{\text {lamina }}$ have been set to 0.3 , while $v_{\text {cytosol }}$ and $v_{\text {nucleoplasm }}$ to 0.4 . The viscosities $\mu_{\text {cytosol }}$ and $\mu_{\text {nucleoplasm }}$ are equal to $3 \times 10^{5}$ Pa-s (Bausch et al. 1999; Drury and Dembo 2001). The cell density $\rho$ has been set to $1,000 \mathrm{~kg} / \mathrm{m}^{3}$ (Fukui et al. 2000), and the viscous friction coefficient $\mu_{\mathrm{adh}}$ is equal $10^{8} \mathrm{~Pa}-\mathrm{s} / \mathrm{m}$. Finally, the intensity of the active strain $e_{a 0}$ and the migration period $T$ have been chosen equal to 0.2 and $600 \mathrm{~s}$, respectively, in order to obtain an average migration velocity of the order of magnitude of the one experimentally observed for HeLa cells (Ronot et al. 2000; Ngalim et al. 2013).

All the parameters of the model have been reported in Table 1 .

\subsection{Cell behaviour and morphology}

As described in Sect. 2.4, the channel is represented by two pseudo-elliptical walls $\left(l_{u w, i}\right.$ and $\left.l_{l w, i}\right)$, whose semi-axes $a$ and $b$ are 30 and $2 \mu \mathrm{m}$ long, respectively.

For the simulations, only two-thirds of the total length of the channel are considered, which corresponds to $40 \mu \mathrm{m}$.

By letting the position of the upper and lower walls centres $\boldsymbol{c}_{u w, i}$ and $\boldsymbol{c}_{l w, i}$ vary, we have tested four channels with different width as follows:

- channel 16 has a width $W_{c, 1}$ of $16 \mu \mathrm{m}$, which is larger than the cell diameter with $c_{u w, 16}(42.5,10 \mu \mathrm{m})$ and $\boldsymbol{c}_{l w, 16}(42.5 \mu \mathrm{m},-10 \mu \mathrm{m})$;

- channel 12 has an intermediate width $W_{c, 2}$ of $12 \mu \mathrm{m}$, which is smaller than the cell diameter and bigger than the nucleus diameter, with $\boldsymbol{c}_{u w, 12}(42.5,8 \mu \mathrm{m})$ and $c_{l w, 12}(42.5,-8 \mu \mathrm{m})$;

- channel 7 has a width $W_{c, 3}$ of $7 \mu \mathrm{m}$, which is slightly smaller than the nucleus diameter with $\boldsymbol{c}_{u w, 7}(42.5$, $5.5 \mu \mathrm{m})$ and $\boldsymbol{c}_{l w, 7}(42.5,-5.5 \mu \mathrm{m})$;

- channel 4 has a width $W_{c, 4}$ of $4 \mu \mathrm{m}$, which is much smaller than the nucleus diameter with $c_{u w, 4}(42.5,4 \mu \mathrm{m})$ and $\boldsymbol{c}_{l w, 4}(42,-4 \mu \mathrm{m})$.

For the first set of simulations, the viscous friction coefficient $\mu_{\text {channel }}$ and the constant $\alpha$ have been set equal to $10^{10} \mathrm{~Pa}-\mathrm{s} / \mathrm{m}$ and 0.1 , respectively.

We have studied the cell behaviour for each of the previous configurations by analysing specific aspects of the confined movement, and the main results are listed in Table 2.

First, we have evaluated the efficiency of the migration in terms of covered distance. In Fig. 3, the total displacement of the frontal edge of the cell is reported for the four simulations. Then, as previously proposed by (Rolli et al. 2010; Scianna et al. 2013), we can classify the cell as permeative, invasive or penetrating. The permeative behaviour is observable for channel 16 and channel 12 (Fig. 2a, b) where the cell reaches the other side of the channel by covering a distance of $38 \mu \mathrm{m}$ in 9,000 s (blue and red lines in Fig. 3, and Movie 1 and Movie 2, respectively). The invasive behaviour occurs when the cell enters into the channel, but it is not able to achieve the other side (Fig. 2c). This is the case of channel 7 where the cell only migrates over $25 \mu \mathrm{m}$ in $6,000 \mathrm{~s}$ (green line in Fig. 3 and Movie 3). Finally, the cell is penetrating (Fig. 2d) 
Table 1 Main geometrical and material parameters of the model

\begin{tabular}{|c|c|c|c|}
\hline Parameter & Description & Value (unit) & References \\
\hline$r_{\text {cell }}$ & Cell radius & $7.5 \mu \mathrm{m}$ & \\
\hline$r_{\text {cortex }}$ & Cortex radius & $7.5 \mu \mathrm{m}$ & \\
\hline$r_{\text {cytosol }}$ & Cytosol radius & $7.25 \mu \mathrm{m}$ & \\
\hline$r_{\text {lamina }}$ & Lamina radius & $4.5 \mu \mathrm{m}$ & \\
\hline$r_{\text {nucleoplasm }}$ & Nucleoplasm radius & $4.4 \mu \mathrm{m}$ & \\
\hline$t_{\text {cortex }}$ & Cortex thickness & $0.25 \mu \mathrm{m}$ & $\begin{array}{l}\text { Pesen and Hoh (2005), } \\
\text { Tinevez et al. (2009), } \\
\text { Jiang and Sun (2013) }\end{array}$ \\
\hline$t_{\text {lamina }}$ & Lamina thickness & $0.1 \mu \mathrm{m}$ & Righolt et al. (2010) \\
\hline$l_{f}$ & $\begin{array}{l}\text { Distance cell centre- } \\
\text { boundary of frontal } \\
\text { adhesion region }\end{array}$ & $4 \mu \mathrm{m}$ & \\
\hline$l_{r}$ & $\begin{array}{l}\text { Distance cell centre- } \\
\text { boundary of rear } \\
\text { adhesion region }\end{array}$ & $4 \mu \mathrm{m}$ & \\
\hline$\Omega_{\text {cell }}$ & Initial cell area & $176.6 \mu \mathrm{m}^{2}$ & \\
\hline$\Omega_{\text {cortex }}$ & Initial cortex area & $11.6 \mu \mathrm{m}^{2}$ & \\
\hline$\Omega_{\text {cytosol }}$ & Initial cytosol area & $101.4 \mu \mathrm{m}^{2}$ & \\
\hline$\Omega_{\text {cytoplasm }}$ & Initial cytoplasm area & $113 \mu \mathrm{m}^{2}$ & \\
\hline$\Omega_{\text {lamina }}$ & Initial lamina area & $2.8 \mu \mathrm{m}^{2}$ & \\
\hline$\Omega_{\text {nucleoplasm }}$ & Initial nucleoplasm area & $60.8 \mu \mathrm{m}^{2}$ & \\
\hline$\Omega_{\text {nucleus }}$ & Initial nucleus area & $63.6 \mu \mathrm{m}^{2}$ & \\
\hline$\Omega_{f}$ & Initial frontal adhesion region area & $31 \mu \mathrm{m}^{2}$ & \\
\hline$\Omega_{r}$ & Initial rear adhesion region area & $31 \mu \mathrm{m}^{2}$ & \\
\hline$E_{\text {cortex }, 0}$ & Nominal cortex Young modulus & $100 \mathrm{~Pa}$ & \\
\hline$E_{\text {cytosol, } 0}$ & Nominal cytosol Young modulus & $10 \mathrm{~Pa}$ & Crick and Hughes (1950) \\
\hline$E_{\text {lamina }, 0}$ & Nominal lamina Young modulus & $3,000 \mathrm{~Pa}$ & $\begin{array}{l}\text { Caille et al. (2002), } \\
\text { Dahl et al. (2008) }\end{array}$ \\
\hline$E_{\text {nucleoplasm }, 0}$ & Nominal nucleoplasm Young modulus & $25 \mathrm{~Pa}$ & Vaziri et al. (2006) \\
\hline$E_{\text {cortex }}$ & Equivalent cortex Young modulus & $15 \mathrm{~Pa}$ & \\
\hline$E_{\text {cytosol }}$ & Equivalent cytosol Young modulus & $8 \mathrm{~Pa}$ & \\
\hline$E_{\text {lamina }}$ & Equivalent lamina Young modulus & $196 \mathrm{~Pa}$ & \\
\hline$E_{\text {nucleoplasm }}$ & Equivalent nucleoplasm Young modulus & $23 \mathrm{~Pa}$ & \\
\hline$v_{\text {cortex }}$ & Cortex Poisson ratio & 0.3 & \\
\hline$v_{\text {cytosol }}$ & Cytosol Poisson ratio & 0.4 & \\
\hline$\nu_{\text {lamina }}$ & Lamina Poisson ratio & 0.3 & \\
\hline$v_{\text {nucleoplasm }}$ & Nucleoplasm Poisson ratio & 0.4 & \\
\hline$\mu_{\text {cytosol }}$ & Cytosol viscosity & $3 \times 10^{5} \mathrm{~Pa}-\mathrm{s}$ & $\begin{array}{l}\text { Bausch et al. (1999), } \\
\text { Drury and Dembo } \\
\text { (2001) }\end{array}$ \\
\hline$\mu_{\text {nucleoplasm }}$ & Nucleoplasm viscosity & $3 \times 10^{5} \mathrm{~Pa}-\mathrm{s}$ & $\begin{array}{l}\text { Bausch et al. (1999), } \\
\text { Drury and Dembo } \\
(2001)\end{array}$ \\
\hline$\rho$ & Cell density & $1,000 \mathrm{~kg} / \mathrm{m}^{3}$ & Fukui et al. (2000) \\
\hline$e_{a 0}$ & Amplitude of the active strain & 0.8 & \\
\hline$T$ & Migration period & $600 \mathrm{~s}$ & \\
\hline$\mu_{\mathrm{adh}}$ & Cell friction coefficient & $10^{8} \mathrm{~Pa}-\mathrm{s} / \mathrm{m}$ & \\
\hline$a$ & Semi-axis of the pseudo-elliptical walls & $30 \mu \mathrm{m}$ & \\
\hline
\end{tabular}


Table 1 continued

\begin{tabular}{|c|c|c|c|}
\hline Parameter & Description & Value (unit) & References \\
\hline$b$ & $\begin{array}{l}\text { Semi-axis of the } \\
\text { pseudo-elliptical walls }\end{array}$ & $2 \mu \mathrm{m}$ & \\
\hline$x_{0}$ & $\begin{array}{l}\text { x-coordinate of the } \\
\text { pseudo-elliptical walls } \\
\text { centre }\end{array}$ & $42.5 \mu \mathrm{m}$ & \\
\hline$y_{\text {uw } 0, i}$ & $\begin{array}{l}\text { y-coordinate of the } \\
\text { upper pseudo-elliptical } \\
\text { wall centre }\end{array}$ & $y_{u w 0,1}: 10 y_{u w 0,2}: 8 y_{u w 0,3}: 6 \quad y_{u w 0,4}: 4 \mu \mathrm{m}$ & \\
\hline$y_{l w 0, i}$ & $\begin{array}{l}y \text {-coordinate of the } \\
\text { lower pseudo-elliptical } \\
\text { wall centre }\end{array}$ & $y_{l w 0,1}:-10 y_{l w 0,2}:-8 y_{l w 0,3}:-6 y_{l w 0,4}:-4 \mu \mathrm{m}$ & \\
\hline$\mu_{\text {channel }}$ & $\begin{array}{l}\text { Channel viscous friction } \\
\text { coefficient }\end{array}$ & $10^{10} \mathrm{~Pa}-\mathrm{s} / \mathrm{m}$ & \\
\hline$\alpha$ & & 0.1 & \\
\hline$W_{c, 16}$ & Width of channel 1 & $16 \mu \mathrm{m}$ & \\
\hline$W_{c, 12}$ & Width of channel 3 & $12 \mu \mathrm{m}$ & \\
\hline$W_{c, 7}$ & Width of channel 3 & $8 \mu \mathrm{m}$ & \\
\hline$W_{c, 4}$ & Width of channel 4 & $4 \mu \mathrm{m}$ & \\
\hline
\end{tabular}

Table 2 Main numerical results for the different channels

\begin{tabular}{lllll}
\hline & Channel 16 & Channel 12 & Channel 7 & Channel 4 \\
\hline Displacement $(\mu \mathrm{m})$ & 38 & 38 & 25 & 7.5 \\
Protrusion average velocity $(\mu \mathrm{m} / \mathrm{s})$ & 0.0055 & 0.0051 & 0.0055 & 0.0053 \\
Contraction average velocity $(\mu \mathrm{m} / \mathrm{s})$ & 0.0102 & 0.0122 & 0.0118 & 0.0115 \\
$t_{\text {contact }}(\mathrm{s})$ & - & 1,950 & 1,250 & 1,220 \\
$t_{\text {penetration }}(\mathrm{s})$ & 3,900 & 4,600 & 4,610 & - \\
$T_{\text {entry }}(\mathrm{s})$ & - & 2,650 & 3,360 & - \\
Maximal ratio cell area/nucleus area & 3.29 & 2.89 & 2.25 & 3.29 \\
Minimal ratio cell area/nucleus area & 2.11 & 1.93 & 1.35 & 2.11 \\
$t_{\text {regime1 }}(\mathrm{s})$ & - & 1,800 & 1,250 & 1,230 \\
$t_{\text {regime2 }}(\mathrm{s})$ & - & 2,450 & 1,350 & 1,250 \\
$t_{\text {regime3 }}(\mathrm{s})$ & - & 2,600 & 1,850 & - \\
\hline
\end{tabular}

when only part of the body (or nothing) penetrates within the channel as it takes place for channel 4 (purple line in Fig. 3 and Movie 4) where the total displacement is only equal to $7.5 \mu \mathrm{m}$.

In Fig. 4, the trend of the cell average velocity is represented. As a general remark, the velocity during the contraction phase is slightly higher than during the contraction phase, since the former only involves the frontal portion of the cytoplasm (see Sect. 2.3). While the average protrusion velocity remains rather constant for all the channels (roughly $5 \cdot 10^{-3} \mu \mathrm{m} / \mathrm{s}$ ), the average contraction velocity varies between a minimal value of about $10^{-2} \mu \mathrm{m} / \mathrm{s}$ for channel 16 (blue line Fig. 4) and a maximal value of $1.2 \cdot 10^{-2} \mu \mathrm{m} / \mathrm{s}$ for channel 12 (red line Fig. 4). Additionally, for channel 7 (green line Fig. 4), we observe a peak of the velocity up to $1.3 \cdot 10^{-2} \mu \mathrm{m} / \mathrm{s}$ at the entrance of the channel, while afterwards the cell acquires again a constant velocity. Such values are of the same order of magnitude of those experimentally observed for HeLa cells (Ronot et al. 2000; Ngalim et al. 2013).

Second, for each configuration, we have quantified the entry time ( $\left.T_{\text {entry }}\right)$, which has been defined by Lautenschläger et al. (Lautenschlager et al. 2009) as the time interval between the first contact of the cell with the channel walls ( $t_{\text {contact }}$ ) and the complete penetration of the cell body within the channel ( $\left.t_{\text {penetration}}\right)$. For channel 16 and channel 4 , such a parameter cannot be evaluated since the cell either does not enter in contact with the channel (channel 16) or does not migrate through it (channel 4). For channel 12 and channel 7, we found 2,650 and 3,360 s respectively, which confirms that the smaller the channel, the more the difficult is for the cell to get in. In fact, the contact cell channel occurs earlier for channel 7 than for channel $12\left(t_{\text {contact }}=1,250 \mathrm{~s}\right.$ versus $t_{\text {contact }}=1,950 \mathrm{~s}$ ), while $t_{\text {penetration }}$ is almost the same 

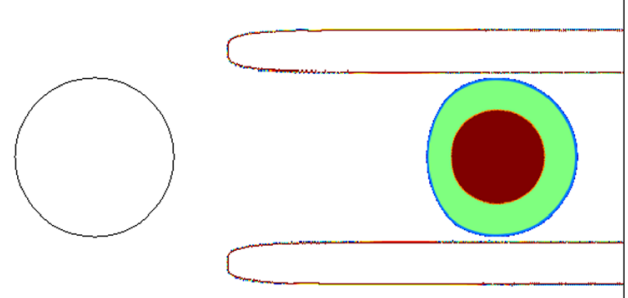

(a) Channel 16 $\mathrm{t}=9000 \mathrm{~s}$
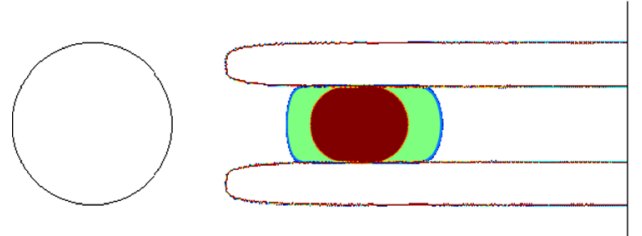

(c) Channel 7 $\mathrm{t}=6000 \mathrm{~s}$

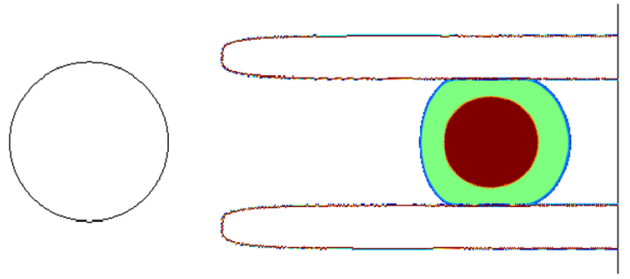

(b) Channel 12 $\mathrm{t}=9000 \mathrm{~s}$

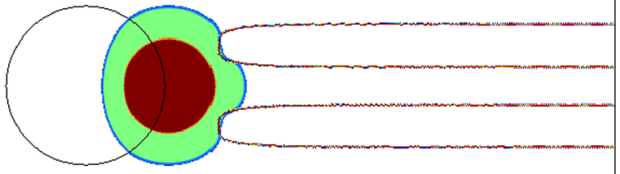

(d) Channel 4 $\mathrm{t}=1800 \mathrm{~s}$

Fig. 2 Snaphots of the permeative (a and $\mathbf{b})$, invasive (c) and penetrating (d) cell

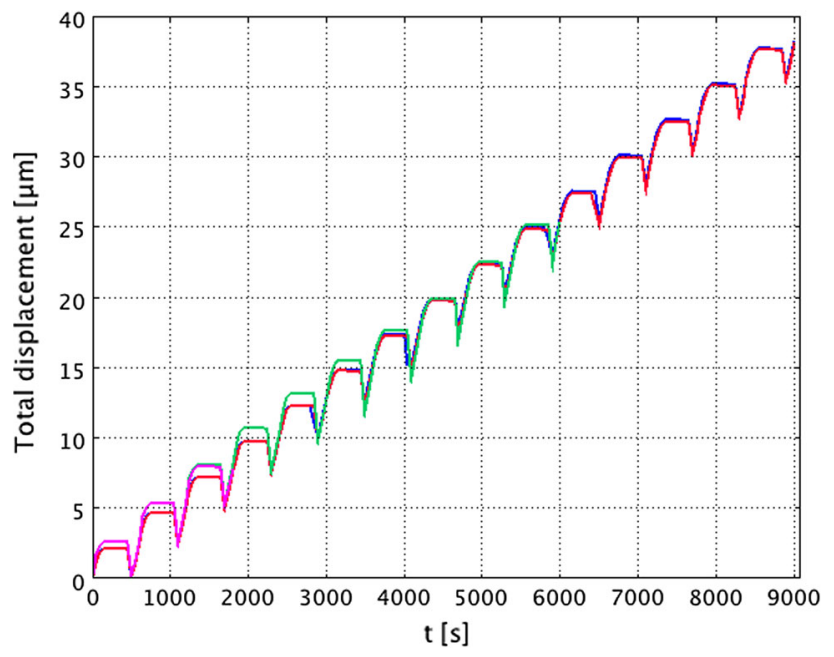

Fig. 3 Total displacement of the cell for channel 16 (blue line), channel 12 (red line), channel 7 (green line) and channel 4 (purple line)

for both channels $\left(t_{\text {penetration }}=4,610 \mathrm{~s}\right.$ versus $t_{\text {penetration }}=$ $4,600 \mathrm{~s})$.

Third, we have evaluated the ratio between the total cell area and the nucleus area. At the initial configuration, such ratio is equal to 2.8 , but it undergoes an oscillatory variation due to the protrusion-contraction movement of the cell. In the case of channel 16 (Fig. 5, blue line), it varies between a maximal value of 3.3 during protrusion and a minimal value of 2.1 during contraction. Here, such values are the same at the end of each phase during the whole simulation since the cell overall deformation is not perturbed by the contact with channel. For channel 12 instead, we observe a decrease of the maximal value of the ratio to 2.9 once the cell has completely

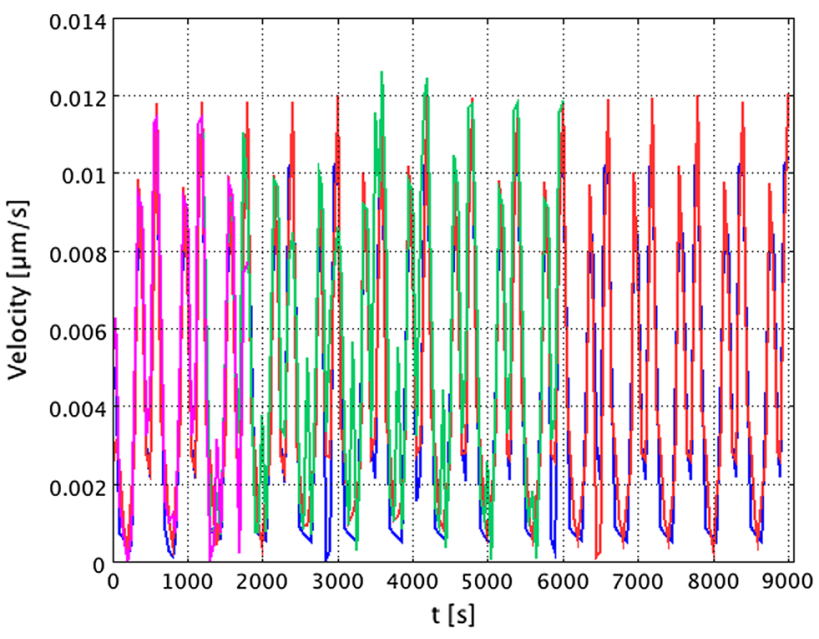

Fig. 4 Migration average velocity of the cell for channel 16 (blue line), channel 12 (red line), channel 7 (green line) and channel 4 (purple line)

entered the channel $\left(\mathrm{t}_{\text {penetration }}=4,600 \mathrm{~s}\right.$, Fig. 5, red line), while the minimal value decreases to 1.9. Such drop is mainly due to a bigger shrinkage of the cell cytoplasm rather than of the nucleus due to the subcellular dimensions of the channel. However, in the case of channel 7 (Fig. 5, green line), both cytoplasm and nucleus contribute to the progressive decrease of the ratio. In fact, the nucleus must squeeze too to move forward since the channel has sub-nuclear dimensions. Then, the maximal and minimal values of the ratio at $t_{\text {penetration }}=$ $4,610 \mathrm{~s}$ decrease down to 2.25 and 1.35 , respectively. For channel 4 (Fig. 5, purple line), the ratio evolution is the same as for channel 16 since the cell is not able to penetrate the channel and neither cytoplasm nor nucleus do not undergo large deformation. 


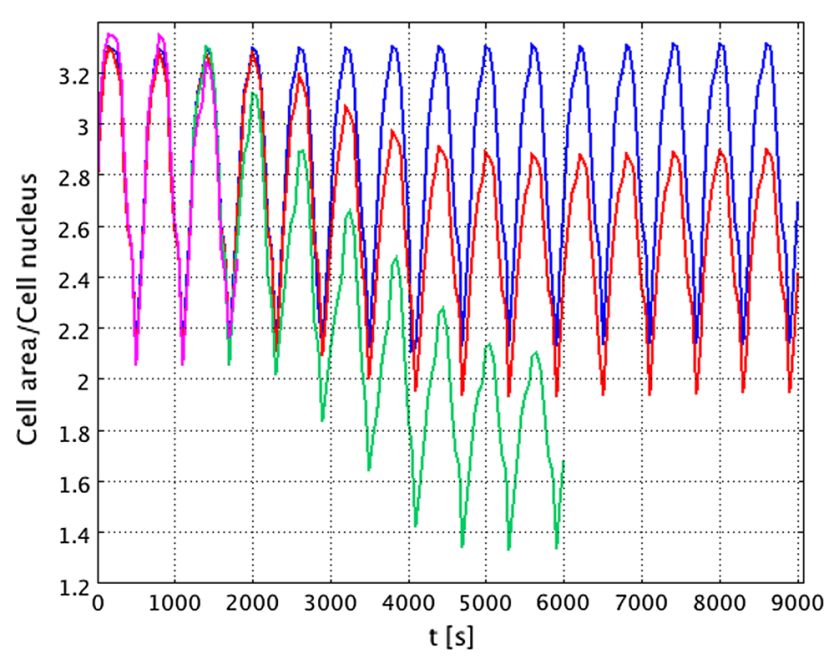

Fig. 5 Ratio between the cell area and the nucleus area for channel 16 (blue line), channel 12 (red line), channel 7 (green line) and channel 4 (purple line)

Finally, we have analysed the morphology of the cell relative to the channel, which can actually be divided into three regimes. The first regime is observed when the length $L_{p}$ of the cell protrusion into the channel is smaller than half the width of the channel $W_{c, i}\left(2 L_{p} / W_{c, i}<1\right)$, and it has been indicated as $t_{\text {regime1 }}$. The second regime occurs when $2 L_{p} / W_{c, i}=1$, and the protrusion is hemicircular with radius equal to $W_{c, I}\left(t_{\text {regime2 }}\right)$. Finally, the third regime is obtained when $2 L_{p} / W_{c, i}>1\left(t_{\text {regime3 }}\right)$. At this point, the first half of the protrusion is rectangular of length $W_{c, i}$ and the second half is hemicircular of radius $L_{c}$.

In the case of channel 16, the migration mode and the morphology of the cell do not change and are very similar to those observed for cell migrating over flat surfaces (Allena and Aubry 2012; Allena 2013). In fact, there is no contact between the cell cortex and the channel walls, and thus, the cell body is not perturbed during its movement. This is not the case for channel 12 and channel 7 where the cell needs to squeeze in order to enter the channel. For channel 12 , regime 1 is observed at $t_{\text {regime } 1}=1,800 \mathrm{~s}$, while $L_{p}$ becomes equal to $W_{c, 2} / 2$ at $t_{\text {regime2 }}=2,450 \mathrm{~s}$. Starting from $t_{\text {regime3 }}=$ $2,600 \mathrm{~s}$, regime 3 is achieved and the protrusion is clearly half rectangular and half hemicircular. For channel 7 (Fig. 6), steps occur earlier. In fact, regime 1 and regime 2 are reached at $t_{\text {regime } 1}=1,250 \mathrm{~s}$ and $t_{\text {regime } 2}=1,350 \mathrm{~s}$, respectively, while regime 3 starts at $t_{\text {regime } 3}=1,850 \mathrm{~s}$. For channel 4 instead, only regime 1 and 2 observed at $t_{\text {regime1 }}=1,230 \mathrm{~s}$ and $t_{\text {regime } 2}=1,250 \mathrm{~s}$, respectively. The reason why regime 3 is not achieved is mainly due to the fact that, despite the cell tries to enter the channel by protruding and contracting, the force $f_{\text {channel }}$ exerted by the channel walls on the cell boundaries is too high. This means that reaching regime 3 is a necessary, but not sufficient condition for the cell to be invasive. In fact, a second necessary condition need to be satisfied, that is, the cell-channel surface force $f_{\text {channel }}$ at $t_{\text {regime3 }}$ must be low enough for the cell to enter.

We have also been able to experimentally observe such changes in morphology for two types of cells using a microchannel-based essay as proposed in (Heuzé et al. 2011). Figure 7a-d shows the successive steps (top view) of bone marrow-derived dendritic cells (BDMCs) migration through a $5 \mu \mathrm{m}$ (Fig. 7a-b) and $1.5 \mu \mathrm{m}$ (Fig. $7 \mathrm{c}$, d) wide microchannel. It is possible to clearly distinguish the three regimes undergone by the whole cell body (Fig. 7b, d) and by the stained nucleus (Fig. 7a, c). Figure 7e shows instead a sagittal view of the successive steps of a HeLa cell migrating through a $20 \mu \mathrm{m}$ wide micro-channel. We observe the deformation undergone by the stained nucleus along the $z$ axis. In fact, in this specific case, the cell is confined in the $x-y$ plane,
Fig. 6 The three regimes of the cell morphology during the migration through channel 7

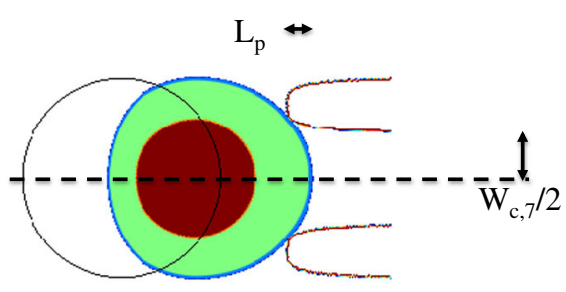

(a) $\mathrm{t}=1250 \mathrm{~s}$

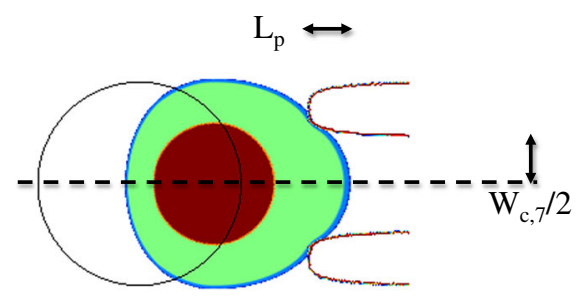

(b) $\mathrm{t}=1350 \mathrm{~s}$

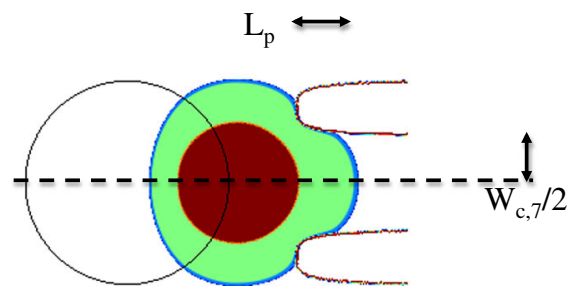

(c) $\mathrm{t}=1850 \mathrm{~s}$ 


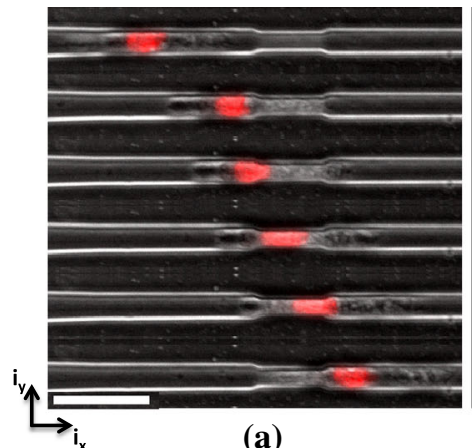

(a)

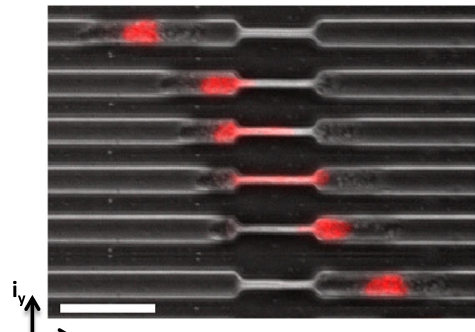

(c)

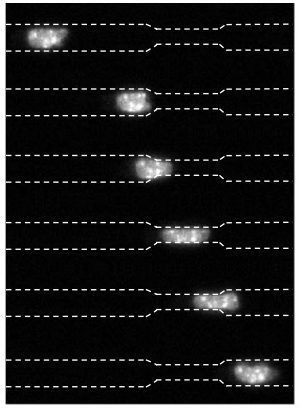

(b)

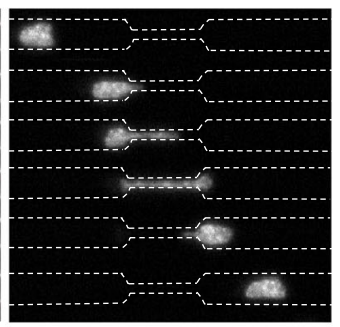

(d)
Fig. 7 (a:d) Top view of successive steps of a bone marrow-derived dendritic cell (BMDC) migration (from the left to the right) through a $5 \mu \mathrm{m} \mathbf{a}-\mathbf{b}$ and $1.5 \mu \mathrm{m} \mathbf{c}-\mathbf{d}$ wide micro-channels. Nuclear staining with Hoechst (a and c) (scale bar: $30 \mu \mathrm{m}$ ) e Sagittal view of successive steps of a HeLa cell entering (from the left to the right) a $20 \mu \mathrm{m}$ wide microchannel (HeLa Histone2B-mcherry (nucleus), MyrPalm-GFP (plasma membrane), scale bar: $15 \mu \mathrm{m})$

Table 3 Values of the mechanical forces for the different channels

\begin{tabular}{|c|c|c|c|c|}
\hline & Channel 16 & Channel 12 & Channel 7 & Channel 4 \\
\hline $\begin{array}{l}\text { Maximal frontal cell-substrate surface } \\
\text { force }(\mathrm{Pa})\end{array}$ & 10 & 10 & 10 & 10 \\
\hline $\begin{array}{l}\text { Maximal rear cell-substrate surface force } \\
(\mathrm{Pa})\end{array}$ & 4 & 4 & 4 & 4 \\
\hline $\begin{array}{l}\text { Maximal cell-channel surface force at } \\
t_{\text {contact }}(\mathrm{Pa})\end{array}$ & - & 3.3 & 3.1 & 7.2 \\
\hline $\begin{array}{l}\text { Maximal cell-channel surface force at } \\
t_{\text {penetration }}(\mathrm{Pa})\end{array}$ & - & 3.3 & 3.9 & - \\
\hline $\begin{array}{l}\text { Average cell-substrate surface force } \\
\text { between } t_{\text {contact }} \text { and } t_{\text {penetration }}(\mathrm{Pa})\end{array}$ & - & 3.3 & 3.3 & 3.3 \\
\hline $\begin{array}{l}\text { Average cell-channel surface force } \\
\text { between } t_{\text {contact }} \text { and } t_{\text {penetration }}(\mathrm{Pa})\end{array}$ & - & 2.5 & 3.2 & $t_{\text {contact }}-t_{\text {regime } 2} 4.5$ \\
\hline $\begin{array}{l}\text { Absolute maximal cell-channel surface } \\
\text { force }(\mathrm{Pa})\end{array}$ & - & 4.2 & 6.2 & 8.6 \\
\hline
\end{tabular}

but also in the $x-z$ plane. Although such an aspect has not been numerically considered so far, we are currently working to improve the model in order to have a three-dimensional representation of the cell and the micro-channel and therefore being able to implement this further confinement

\subsection{Mechanical forces}

In this section, we try to evaluate the cell-substrate and cellchannel surface forces, in particular during the time interval between $t_{\text {contact }}$ and $t_{\text {penetration in which }} t_{\text {regime } 3}$ is included. The main values are summarized in Table 3 .

Some general remarks may be pointed out:

- given the asymmetry of the active strain (Sect. 2.3) and the equation expressing the cell-substrate surface forces (Eq. 3), we found 10 and $4 \mathrm{~Pa}$, respectively, at the front and rear edge of the cell. Additionally, such values do not change from one configuration;

- the cell-channel surface force increases as the channel width $W_{c, i}$ decreases (maximal absolute value of 4.25 , 
6.25 and $8.5 \mathrm{~Pa}$ for channel 12, channel 7 and channel 4 , respectively);

- as mentioned in Sect. 3.1, the necessary condition for the cell to be invasive is that the average cell-channel surface force at $t_{\text {regime}} 3$ must be lower than the average cell-substrate surface force at the same time point. This allows the cell to pull enough to penetrate within the channel without being obstructed by the channel. Since $t_{\text {regime3 }}$ is included in the time interval between $t_{\text {contact }}$ and $t_{\text {penetration}}$, we have calculated the average cell-channel surface force during this period. For channel 12 and channel 7, we have found an average value for the cell-channel surface force of about $2.5 \mathrm{~Pa}$ and 3.2, respectively, which is lower than the average cell-substrate surface force of 3.3 Pa. As a result, the cell is able to enter the channel. For channel 4, since the cell-channel surface force between $t_{\text {contact }}$ and $t_{\text {penetration }}$ cannot be calculated, we have evaluated it between $t_{\text {contact }}$ and $t_{\text {regime2 }}$ finding an average value of $4.5 \mathrm{~Pa}$ and a maximal value of $8.6 \mathrm{~Pa}$, which is twice the cell-substrate surface force. Therefore, the cell is stuck at the entrance of the channel and shows a penetrating behaviour;

- once the cell has completely penetrated into the channel, the upper and lower central boundaries of the cell come very close or directly in contact with the nucleus, which is the stiffest component of the system. Then, a higher cellchannel surface force is necessary at this specific region to maintain the cell squeezing during the whole migration process and in order for the cell to be permeative. This is the case for channel 12 for which the cell is able to reach the opposite end of the channel (Movie 5). However, for channel 7 , the cell-channel surface force is slightly higher at the rear of the cell. Thus, the cell is slowed down and shows a penetrating behaviour (Movie 6).

For channel 16, only the cell-substrate surface force can be evaluated while the cell-channel surface force is null since no contact between the cell boundaries and the channel walls occurs.

\section{Conclusions}

In this paper, we have proposed a 2D mechanical model to simulate the migration of HeLa cell under confinement. The model reproduces the set-up used in a micro-channel assay as presented in (Heuzé et al. 2011). As in our previous works (Allena and Aubry 2012; Allena 2013), the cell is modelled as continuum and a standard Maxwell model is used to describe the mechanical behaviour of the cytoplasm (including active strains) and the nucleus. The cell is able to cyclically develop protrusion-contraction strains, which are synchronized with the adhesion forces between the cell and the substrate. By approaching the channel, which is represented here by two pseudo-elliptical rigid walls, the cell is submitted to an additional viscous force. We have tested four channels whose dimensions in terms of width are larger than the cell diameter (channel 16), sub-cellular (channel 12), sub-nuclear (channel 7) and much smaller than the nucleus diameter (channel 4). We have analysed the cell behaviour and classified it as permeative (channel 16 and channel 12), invasive (channel 7 ) or penetrating (channel 4 ) according to the distance covered by the cell inside the channel. From a morphological point of view, we have identified three different regimes in relation to the ratio between the cell protrusion length in the channel and the width of the channel. Additionally, we have evaluated the evolution of the cell shape and the cell-substrate and cellchannel surface forces between the first contact between the cell and the channel $\left(t_{\text {contact }}\right)$ and the complete penetration of the cell body within the channel $\left(t_{\text {penetration }}\right)$.

Therefore, we have been able to define the necessary conditions in order for the cell to be invasive or permeative. In the first case, two main conditions must be satisfied: i) regime 3 (i.e. cell protrusion length in the channel larger than half the channel width) has to be achieved, and ii) simultaneously, the cell-substrate surface force must be higher than the cellchannel surface force so that the cell is able to pull on the substrate and enter into the channel. For the second behaviour to occur, a further condition must be satisfied, that is, the cell-channel surface force during the whole migration has to be maximal along the upper and lower central boundaries of the cell. Those boundaries may come very close or directly in contact with the cell nucleus, which is the stiffest component of the system. Then, a larger force is required to maintain the squeezed cell shape.

Despite the consistent results shown in the present paper, our model still presents some limitations. Firstly, the geometry is $2 \mathrm{D}$, which does not allow considering a top-roofed micro-channel and the cell deformation in the third direction. Secondly, the active strains of protrusion and contraction have been defined through a sinusoidal function, which may lead to a rather stable periodic deformation of the cytoplasm and consequently of the nucleus. In order to control the effects of such a phenomenon, some stochastic active input close to cell perception may be introduced and improve the global movement. Finally, so far all the cell components have been considered as viscoelastic materials. However, the nucleus may be able to adapt its deformation to the forces exerted by the micro-channel on the cell boundaries. Therefore, a viscoplastic behaviour with restoration (Mandel 1972; Lubliner 2008) would probably be more appropriate. We are currently working on this aspect in order to be able to investigate the ability of the cell to penetrate micro-channels with significant sub-nuclear dimensions. 


\section{Appendix}

\subsection{Geometry of the cell}

For any spatial point $\boldsymbol{p}$, the four components of the cell body (the cortex $\Omega_{\text {cortex }}$, the cytosol $\Omega_{\text {cytosol }}$, the lamina $\Omega_{\text {lamina }}$ and the nucleoplasm $\Omega_{\text {nucleoplasm }}$ ) are described through characteristic functions (i.e. composition of a Heaviside and a level set function (Allena 2013) as follows

$h_{\text {cortex }}(\boldsymbol{p})= \begin{cases}1 & \text { if } r_{\text {cytoplasm }}^{2}<\left\|\boldsymbol{p}-\boldsymbol{c}_{\text {cell }}\right\|<r_{\text {cortex }}^{2} \\ 0 & \text { otherwise }\end{cases}$

$h_{\text {cytosol }}(\boldsymbol{p})= \begin{cases}1 & \text { if } r_{\text {lamina }}^{2}<\left\|\boldsymbol{p}-\boldsymbol{c}_{\text {cell }}\right\|<r_{\text {cytosol }}^{2} \\ 0 & \text { otherwise }\end{cases}$

$h_{\text {lamina }}(\boldsymbol{p})= \begin{cases}1 & \text { if } r_{\text {nucleoplasm }}^{2}<\left\|\boldsymbol{p}-\boldsymbol{c}_{\text {cell }}\right\|<r_{\text {lamina }}^{2} \\ 0 & \text { otherwise }\end{cases}$

$h_{\text {nucleoplasm }}(\boldsymbol{p})= \begin{cases}1 & \text { if }\left\|\boldsymbol{p}-\boldsymbol{c}_{\text {cell }}\right\|<r_{\text {nucleoplasm }}^{2} \\ 0 & \text { otherwise }\end{cases}$

where $\boldsymbol{p}=\boldsymbol{x}-\boldsymbol{u}$, with $\boldsymbol{x}$ and $\boldsymbol{u}$ being, respectively, the actual position and the displacement, $\boldsymbol{c}_{\text {cell }}$ is the cell centre and $r_{\text {cortex }}, r_{\text {cytosol }}, r_{\text {lamina }}$ and $r_{\text {nucleoplasm }}$ are the external radius of the cell cortex, the cytosol, the nuclear lamina and nucleoplasm, respectively (Fig. 1a). Therefore, the cytoplasm $\Omega_{\text {cytoplasm }}$ and the nucleus $\Omega_{\text {nucleus }}$ domains are defined by the following characteristic functions

$h_{\text {cytoplasm }}(\boldsymbol{p})=h_{\text {cortex }}(\boldsymbol{p})+h_{\text {cytosol }}(\boldsymbol{p})$

$h_{\text {nucleus }}(\boldsymbol{p})=h_{\text {lamina }}(p)+h_{\text {nucleoplasm }}(\boldsymbol{p})$

The frontal portion of cytosol where the polymerization of the actin filaments takes place is described as follows

$h_{\text {cytosol,front }}(\boldsymbol{p})=\begin{array}{ll}h_{\text {cytosol }} & \text { if } \boldsymbol{p}>\boldsymbol{c}_{\text {cell }} \\ 0 & \text { otherwise }\end{array}$

The frontal $\left(\Omega_{f}\right)$ and rear $\left(\Omega_{r}\right)$ adhesion regions are also defined by two characteristic functions as

$$
\begin{aligned}
& h_{f}(\boldsymbol{p})=\begin{array}{ll}
1 & \left(\boldsymbol{p}-\boldsymbol{c}_{\text {cell }}, \boldsymbol{i}_{x}\right)>l_{f} \\
0 & \text { otherwise }
\end{array} \\
& h_{r}(\boldsymbol{p})=\begin{array}{cl}
1 & \left(\boldsymbol{p}-\boldsymbol{c}_{\text {cell }}, \boldsymbol{i}_{x}\right)<-l_{r} \\
0 & \text { otherwise }
\end{array}
\end{aligned}
$$

with $l_{f}$ and $l_{r}$ the distances of $\boldsymbol{c}_{\text {cell }}$ from the boundaries of $\Omega_{f}$ and $\Omega_{r}$, respectively, (Fig. 1b). As soon as the cell moves, the argument $\boldsymbol{p}$ is replaced by $\boldsymbol{x}-\boldsymbol{u}$, with $\boldsymbol{x}$ the actual spatial position and $\boldsymbol{u}$ the displacement.

\subsection{Nucleus constitutive law}

As mentioned in Sect. 2.2, the nucleus is described through a viscoelastic constitutive equation based on a standard
Maxwell model including a solid phase (i.e. the lamina) and a fluid phase (i.e. the nucleoplasm) (Fig. 8).

The Cauchy stress $\sigma_{\text {nucleus }}$ and the deformation tensor $\boldsymbol{F}_{\text {nucleus }}$ in the nucleus are defined by

$\sigma_{\text {nucleus }}=\sigma_{\text {lamina }}+\sigma_{\text {nucleoplasm }}$

$\boldsymbol{F}_{\text {nucleus }}=\boldsymbol{D}_{p} \boldsymbol{u}+\boldsymbol{I}=\boldsymbol{F}_{\text {lamina }}=\boldsymbol{F}_{\text {nucleoplasm }}$

where $\boldsymbol{D}_{\boldsymbol{p}} \boldsymbol{u}={ }_{m=1}^{3} \frac{\partial \boldsymbol{u}}{\partial p_{m}} \otimes \boldsymbol{i}_{m}$, with $\boldsymbol{u}$ the displacement and $\boldsymbol{I}$ the identity matrix (Holzapfel 2000; Taber 2004), and $\boldsymbol{F}_{\text {nucleoplasm }}=\boldsymbol{F}_{\text {nucleoplasm }, e} \boldsymbol{F}_{\text {nucleoplasm }, v}$. The solid part of the stress $\sigma_{\text {lamina }}$ in the lamina reads

$\boldsymbol{\sigma}_{\text {lamina }}=\frac{1}{J_{\text {lamina }}} \boldsymbol{F}_{\text {lamina }} \boldsymbol{S}_{\text {lamina }} \boldsymbol{F}_{\text {lamina }}^{T}$

where $J_{\text {lamina }}$ is the determinant of $\boldsymbol{F}_{\text {lamina }}$ and $\boldsymbol{S}_{\text {lamina }}$ is the second Piola-Kirchoff stress tensor, which is computed as an isotropic hyperelastic Saint Venant material as follows

$\boldsymbol{S}_{\text {lamina }}=\lambda_{\text {lamina }} \operatorname{Tr}\left(\boldsymbol{E}_{\text {lamina }}\right) \boldsymbol{I}+2 \mu_{\text {lamina }} \boldsymbol{E}_{\text {lamina }}$

with $\lambda_{\text {lamina }}, \mu_{\text {lamina }}$ and $\boldsymbol{E}_{\text {lamina }}$ the Lame's coefficients and the Green-Lagrange strain tensor of the solid phase, respectively.

The fluid part of the stress $\sigma_{\text {nucleoplasm }}$ in the nucleoplasm can be expressed as

$\boldsymbol{\sigma}_{\text {nucleoplasm }}=2 \mu_{\text {nucleoplasm }} \boldsymbol{D}_{\text {nucleoplasm,v }}$

with $\mu_{\text {nucleoplasm, }}$ the viscosity of the nucleoplasm and the eulerian strain rate $\boldsymbol{D}_{\text {nucleoplasm, } v}$ is computed from the strain gradient velocity as

$$
\begin{aligned}
2 \boldsymbol{D}_{\text {nucleoplasm }, v}= & \dot{\boldsymbol{F}}_{\text {nucleoplasm }, v} \boldsymbol{F}_{\text {nucleoplasm }, v}^{-1} \\
& +\boldsymbol{F}_{\text {nucleoplasm }, v}^{-T} \dot{\boldsymbol{F}}_{\text {nucleoplasm }, v}^{T}
\end{aligned}
$$

\subsection{Cytoplasm constitutive law}

The cytoplasm is composed by two phases: i) a solid phase represented by the cell cortex and ii) a fluid phase represented by the viscous cytosol with the embedded organelles such as the actin filaments that undergo the active strains (Fig. 8). It is assumed that the Cauchy stress $\sigma_{\text {cytoplasm }}$ and the deformation tensor $\boldsymbol{F}_{\text {cytoplasm }}$ read

$\sigma_{\text {cytoplasm }}=\sigma_{\text {cortex }}+\sigma_{\text {cytosol }}$

$\boldsymbol{F}_{\text {cytoplasm }}=\boldsymbol{F}_{\text {cortex }}=\boldsymbol{F}_{\text {cytosol }}$

Additionally, the fluid deformation tensor $\boldsymbol{F}_{\text {cytosol }}$ is multiplicatively decomposed as follows

$\boldsymbol{F}_{\text {cytosol }}=\boldsymbol{F}_{\text {cytosol }, v} \boldsymbol{F}_{\text {cytosol }, e} \boldsymbol{F}_{\mathrm{cytosol}, a}$

where $e$ and $v$ stand for elastic and viscous, respectively.

The solid stress $\sigma_{\text {cortex }}$ in the organelles can be written as

$\boldsymbol{\sigma}_{\text {cortex }}=\frac{1}{J_{\text {cortex }}} \boldsymbol{F}_{\text {cortex }} \boldsymbol{S}_{\text {cortex }} \boldsymbol{F}_{\text {cortex }}^{T}$ 
Fig. 8 Symbolic schemas for the standard Maxwell models used to describe the nucleus (top) and the cytoplasm (bottom) behaviours

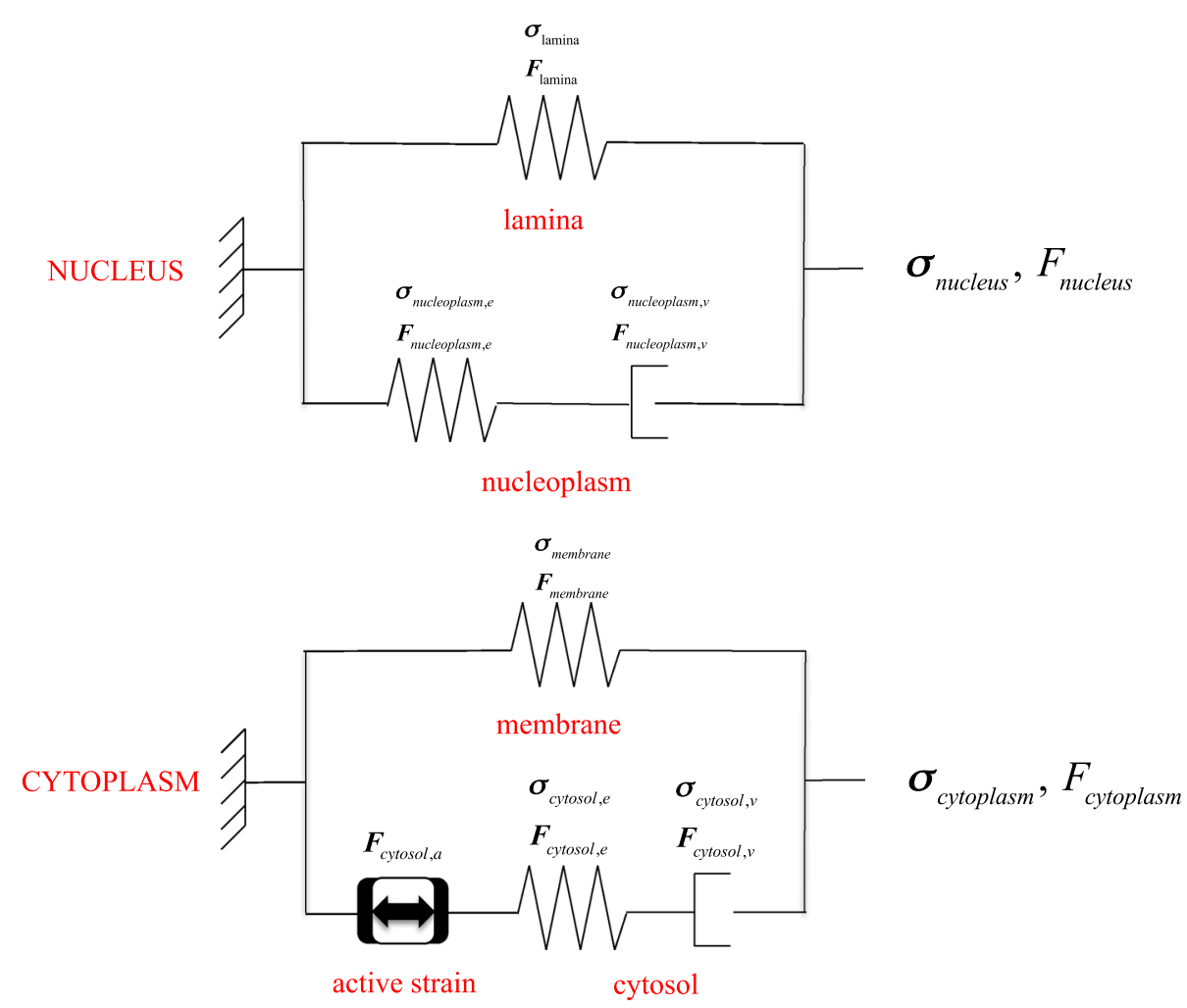

with $J_{\text {cortex }}$ the determinant of $\boldsymbol{F}_{\text {cortex }}$ and $\boldsymbol{S}_{\text {cortex }}$ the second Piola-Kirchoff stress tensor, which, similarly to the nucleus (Sect. 5.2), is defined as an isotropic hyperplastic Saint Venant material as follows

$S_{\text {cortex }}=\lambda_{\text {cortex }} \operatorname{Tr}\left(\boldsymbol{E}_{\text {cortex }}\right) \boldsymbol{I}+2 \boldsymbol{\mu}_{\text {cortex }} \boldsymbol{E}_{\text {cortex }}$

where $\lambda_{\text {cortex }}, \mu_{\text {cortex }}$ and $\boldsymbol{E}_{\text {cortex }}$ the Lame's coefficients and the Green-Lagrange strain tensor of the solid phase, respectively.

Finally, the fluid stress $\sigma_{\text {cytosol }}$ in the cytosol reads

$\boldsymbol{\sigma}_{\text {cytosol }}=2 \mu_{\text {cytosol }} \boldsymbol{D}_{\text {cytosol }, v}$

with $\mu_{\text {cytosol }}$ the viscosity of the cytosol and $\boldsymbol{D}_{\text {cytosol, } v}$ the eulerian strain rate expressed as follows

$2 \boldsymbol{D}_{\text {cytosol }, v}=\dot{\boldsymbol{F}}_{\text {cytosol }, v} \boldsymbol{F}_{\text {cytosol }, v}^{-1}+\boldsymbol{F}_{\text {cytosol }, v}^{-T} \dot{\boldsymbol{F}}_{\text {cytosol }, v}^{T}$

\subsection{Micro-channel geometry}

As mentioned in Sect. 2.4, the micro-channel domain $\Omega_{\text {channel }}$ is modelled as two pseudo-elliptical rigid walls: a upper one $\left(\Omega_{u w}\right)$ and a lower one $\left(\Omega_{l w}\right)$. They are described through two characteristic functions as follows

$$
\begin{aligned}
& h_{u w, i}(\boldsymbol{p})=\begin{array}{ll}
1 & \text { if } l_{u w, i}<1 \\
0 & \text { otherwise }
\end{array} \\
& h_{l w, i}(\boldsymbol{p})=\begin{array}{ll}
1 & \text { if } l_{l w, i}<1 \\
0 & \text { otherwise }
\end{array}
\end{aligned}
$$

where the subscript ' $i$ ' indicates the number of the channel, and $l_{u w, i}$ and $l_{l w}$ are two level set functions expressed as

$$
\begin{aligned}
& l_{u w, i}=\left({\frac{x-x_{0}}{a}}^{4}+\left(\frac{y-y_{u w 0, i}}{b}{ }^{4}\right.\right. \\
& l_{l w, i}=\left({\frac{x-x_{0}}{a}}^{4}+\left(\frac{y+y_{l w 0, i}}{b}{ }^{4}\right.\right.
\end{aligned}
$$

with $a$ and $b$ are the semi-axes of the pseudo-elliptical walls with centres $\boldsymbol{c}_{u w, i}\left(x_{0}, y_{u w 0, i}\right)$ and $\boldsymbol{c}_{l w, i}\left(x_{0}, y_{l w 0, i}\right)$. Thus, the micro-channel is the composition of the two previous characteristic functions as follows

$\Omega_{\text {channel }}=h_{u w, i}(\boldsymbol{p})+h_{l w, i}(\boldsymbol{p})$

The c outward normals $\boldsymbol{n}_{u w}$ and $\boldsymbol{n}_{l w}$ to the boundary $\partial \Omega_{u w}$ and $\partial \Omega_{l w}$, respectively, given by

$\boldsymbol{n}_{u w, i}=h^{\prime}\left(l_{u w, i}\right) \frac{\nabla l_{u w, i}}{\left\|\nabla l_{u w, i}\right\|}$
$\boldsymbol{n}_{l w, i}=h^{\prime}\left(l_{l w, i}\right) \frac{\nabla l_{l w, i}}{\left\|\nabla l_{l w, i}\right\|}$

where $h^{\prime}$ indicates the Dirac function.

\section{References}

Allena R (2013) Cell migration with multiple pseudopodia: temporal and spatial sensing models. Bull Math Biol 75:288-316. doi:10. 1007/s11538-012-9806-1 
Allena R, Aubry D (2012) "Run-and-tumble" or "look-and-run"? A mechanical model to explore the behavior of a migrating amoeboid cell. J Theor Biol 306:15-31. doi:10.1016/j.jtbi.2012.03.041

Bausch AR, Möller W, Sackmann E (1999) Measurement of local viscoelasticity and forces in living cells by magnetic tweezers. Biophys J 76:573-579

Caille N, Thoumine O, Tardy Y, Meister J-J (2002) Contribution of the nucleus to the mechanical properties of endothelial cells. J Biomech 35:177-187

Christensen RM (1991) Mechanics of composite materials. Krieger Publishing Company, NY

Crick FHC, Hughes AFW (1950) The physical properties of cytoplasm. Exp Cell Res 1:37-80. doi:10.1016/0014-4827(50)90048-6

Dahl KN, Ribeiro AJS, Lammerding J (2008) Nuclear shape, mechanics, and mechanotransduction. Circ Res 102:1307-1318. doi:10. 1161/CIRCRESAHA.108.173989

Drury JL, Dembo M (2001) Aspiration of human neutrophils: effects of shear thinning and cortical dissipation. Biophys J 81:3166-3177

Egeblad M, Rasch MG, Weaver VM (2010) Dynamic interplay between the collagen scaffold and tumor evolution. Curr Opin Cell Biol 22:697-706. doi:10.1016/j.ceb.2010.08.015

Erler JT, Weaver VM (2009) Three-dimensional context regulation of metastasis. Clin Exp Metastas 26:35-49. doi:10.1007/ s10585-008-9209-8

Faure-André G, Vargas P, Yuseff M-I et al (2008) Regulation of dendritic cell migration by CD74, the MHC class II-associated invariant chain. Science 322:1705-1710. doi:10.1126/science.1159894

Friedl P, Wolf K (2010) Plasticity of cell migration: a multiscale tuning model. J Cell Biol 188:11-19. doi:10.1083/jcb.200909003

Friedl P, Wolf K, Lammerding J (2011) Nuclear mechanics during cell migration. Curr Opin Cell Biol 23:55-64. doi:10.1016/j.ceb.2010. 10.015

Fukui Y, Uyeda TQP, Kitayama C, Inoué S (2000) How well can an amoeba climb? PNAS 97:10020-10025. doi:10.1073/pnas.97.18. 10020

Giverso C, Grillo A, Preziosi L, Influence of nucleus deformability on cell entry into cylindrical structures. Biomech Model Mechanobiol, pp 1-22. doi:10.1007/s10237-013-0510-3

Gracheva ME, Othmer HG (2004) A continuum model of motility in ameboid cells. Bull Math Biol 66:167-193. doi:10.1016/j.bulm. 2003.08.007

Hawkins RJ, Piel M, Faure-Andre G et al (2009) Pushing off the walls: a mechanism of cell motility in confinement. Phys Rev Lett 102:058103. doi:10.1103/PhysRevLett.102.058103

Hawkins RJ, Voituriez R (2010) Mechanisms of cell motion in confined geometries. Math Model Nat Phenom 5:84-105. doi:10.1051/ $\mathrm{mmnp} / 20105104$

Heuzé ML, Collin O, Terriac E et al (2011) Cell migration in confinement: a micro-channel-based assay. Methods Mol Biol 769:415-434. doi:10.1007/978-1-61779-207-6_28

Holzapfel GA (2000) Nonlinear solid mechanics: a continuum approach for engineering, 1st edn. Wiley, London

Ilina O, Bakker G-J, Vasaturo A et al (2011) Two-photon lasergenerated microtracks in 3D collagen lattices: principles of MMPdependent and -independent collective cancer cell invasion. Phys Biol 8:015010. doi:10.1088/1478-3975/8/1/015010

Irimia D, Charras G, Agrawal N et al (2007) Polar stimulation and constrained cell migration in microfluidic channels. Lab Chip 7:17831790. doi:10.1039/b710524j

Irimia D, Toner M (2009) Spontaneous migration of cancer cells under conditions of mechanical confinement. Integr Biol (Camb) 1:506512. doi:10.1039/b908595e

Jiang H, Sun SX (2013) Cellular pressure and volume regulation and implications for cell mechanics. Biophys J 105:609-619. doi:10. 1016/j.bpj.2013.06.021
Larson RG (1998) The structure and rheology of complex fluids. Oxford University Press, USA

Lautenschlager F, Paschke S, Schinkinger S et al (2009) The regulatory role of cell mechanics for migration of differentiating myeloid cells. Proc Natl Acad Sci 106:15696-15701. doi:10.1073/pnas. 0811261106

Lubliner J (2008) Plasticity theory. Dover Publications, New York

Mandel J (1972) Plasticité classique et viscoplasticité: course held at the Department of Mechanics of Solids, September-October, 1971. Springer, Berlin

McElwain DLS (1978) A re-examination of oxygen diffusion in a spherical cell with michaelis-menten oxygen uptake kinetics. J Theor Biol 71:255-263. doi:10.1016/0022-5193(78)90270-9

McElwain DLS, Callcott R, Morris LE (1979) A model of vascular compression in solid tumours. J Theor Biol 78:405-415. doi:10.1016/ 0022-5193(79)90339-4

McElwain DLS, Ponzo PJ (1977) A model for the growth of a solid tumor with non-uniform oxygen consumption. Math Biosci 35:267279. doi:10.1016/0025-5564(77)90028-1

Mogilner A (2009) Mathematics of cell motility: have we got its number? J Math Biol 58:105-134. doi:10.1007/s00285-008-0182-2

Ngalim SH, Magenau A, Zhu Y et al (2013) Creating adhesive and soluble gradients for imaging cell migration with fluorescence microscopy. J Vis Exp. doi:10.3791/50310

Pesen D, Hoh JH (2005) Micromechanical architecture of the endothelial cell cortex. Biophys J 88:670-679. doi:10.1529/biophysj.104. 049965

Phillipson M, Heit B, Colarusso P et al (2006) Intraluminal crawling of neutrophils to emigration sites: a molecularly distinct process from adhesion in the recruitment cascade. J Exp Med 203:2569-2575. doi:10.1084/jem.20060925

Provenzano PP, Inman DR, Eliceiri KW et al (2008) Collagen density promotes mammary tumor initiation and progression. BMC Med 6:11. doi:10.1186/1741-7015-6-11

Rangarajan R, Zaman MH (2008) Modeling cell migration in 3D. Cell Adhes Migr 2:106-109

Recho P, Putelat T, Truskinovsky L (2013) Contraction-driven cell motility. Phys Rev Lett 111:108102. doi:10.1103/PhysRevLett.111. 108102

Recho P, Truskinovsky L (2013) An asymmetry between pushing and pulling for crawling cells. arXiv:1302.4002 [cond-mat, physics:physics, q-bio]

Righolt CH, Raz V, Vermolen BJ et al (2010) Molecular image analysis: quantitative description and classification of the nuclear lamina in human mesenchymal stem cells. Int J Mol Imaging. doi:10.1155/ 2011/723283

Rolli CG, Seufferlein T, Kemkemer R, Spatz JP (2010) Impact of tumor cell cytoskeleton organization on invasiveness and migration: a microchannel-based approach. PLoS ONE 5:e8726. doi:10.1371/ journal.pone. 0008726

Ronot X, Doisy A, Tracqui P (2000) Quantitative study of dynamic behavior of cell monolayers during in vitro wound healing by optical flow analysis. Cytometry 41:19-30

Sakamoto Y, Prudhomme S, Zaman MH (2011) Viscoelastic gel-strip model for the simulation of migrating cells. Ann Biomed Eng 39:2735-2749. doi:10.1007/s10439-011-0360-z

Schaub S, Bohnet S, Laurent VM et al (2007) Comparative maps of motion and assembly of filamentous actin and myosin II in migrating cells. Mol Biol Cell 18:3723-3732. doi:10.1091/mbc.E06-09-0859

Scianna M, Preziosi L (2013) Modeling the influence of nucleus elasticity on cell invasion in fiber networks and microchannels. J Theor Biol 317:394-406. doi:10.1016/j.jtbi.2012.11.003

Scianna M, Preziosi L, Wolf K (2013) A cellular potts model simulating cell migration on and in matrix environments. Math Biosci Eng $10: 235-261$ 
Stokes CL, Lauffenburger DA (1991) Analysis of the roles of microvessel endothelial cell random motility and chemotaxis in angiogenesis. J Theor Biol 152:377-403. doi:10.1016/S0022-5193(05)80201-2

Stokes CL, Lauffenburger DA, Williams SK (1991) Migration of individual microvessel endothelial cells: stochastic model and parameter measurement. J Cell Sci 99(Pt 2):419-430

Taber LA (2004) Nonlinear theory of elasticity: applications in biomechanics. World Scientific Pub Co Inc., Singapore

Taylor AM, Blurton-Jones M, Rhee SW et al (2005) A microfluidic culture platform for CNS axonal injury, regeneration and transport. Nat Methods 2:599-605. doi:10.1038/nmeth777

Tinevez J-Y, Schulze U, Salbreux G, et al. (2009) Role of cortical tension in bleb growth. PNAS pnas.0903353106. doi:10.1073/pnas. 0903353106

Tozluoğlu M, Tournier AL, Jenkins RP et al (2013) Matrix geometry determines optimal cancer cell migration strategy and modulates response to interventions. Nat Cell Biol 15:751-762. doi:10.1038/ ncb2775

Tranquillo RT, Lauffenburger DA (1987) Stochastic model of leukocyte chemosensory movement. J Math Biol 25:229-262
Tranquillo RT, Lauffenburger DA, Zigmond SH (1988) A stochastic model for leukocyte random motility and chemotaxis based on receptor binding fluctuations. J Cell Biol 106:303-309

Vaziri A, Lee H, Mofrad MRK (2006) Deformation of the cell nucleus under indentation: mechanics and mechanisms. J Mater Res 21:2126-2135. doi:10.1557/jmr.2006.0262

Wolf K, Alexander S, Schacht V et al (2009) Collagen-based cell migration models in vitro and in vivo. Semin Cell Dev Biol 20:931-941. doi:10.1016/j.semcdb.2009.08.005

Zaman MH, Kamm RD, Matsudaira P, Lauffenburger DA (2005) Computational model for cell migration in three-dimensional matrices. Biophys J 89:1389-1397. doi:10.1529/biophysj.105.060723

Zaman MH, Matsudaira P, Lauffenburger DA (2007) Understanding effects of matrix protease and matrix organization on directional persistence and translational speed in three-dimensional cell migration. Ann Biomed Eng 35:91-100. doi:10.1007/s10439-006-9205-6

Zaman MH, Trapani LM, Sieminski AL et al (2006) Migration of tumor cells in $3 \mathrm{D}$ matrices is governed by matrix stiffness along with cell-matrix adhesion and proteolysis. Proc Natl Acad Sci USA 103:10889-10894. doi:10.1073/pnas.0604460103 